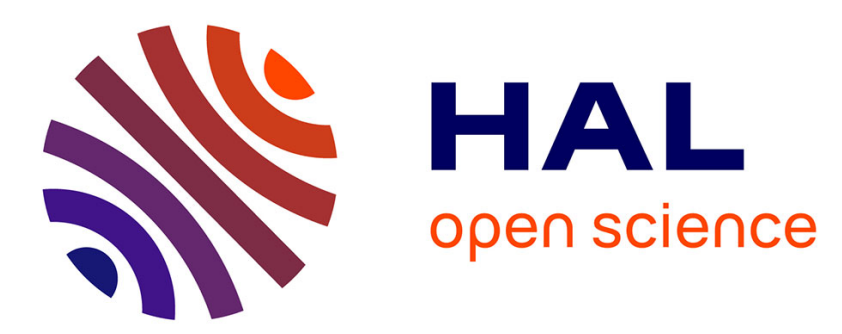

\title{
Consumer exposure to phthalates from paper packaging - an integrated approach
}

\author{
Maria F Poças, Jorge C Oliveira, Joel R Pereira, Timothy Hogg
}

\section{To cite this version:}

Maria F Poças, Jorge C Oliveira, Joel R Pereira, Timothy Hogg. Consumer exposure to phthalates from paper packaging - an integrated approach. Food Additives and Contaminants, 2010, 27 (10), pp.1451. 10.1080/19440049.2010.490790 . hal-00604873

\section{HAL Id: hal-00604873 https://hal.science/hal-00604873}

Submitted on 30 Jun 2011

HAL is a multi-disciplinary open access archive for the deposit and dissemination of scientific research documents, whether they are published or not. The documents may come from teaching and research institutions in France or abroad, or from public or private research centers.
L'archive ouverte pluridisciplinaire HAL, est destinée au dépôt et à la diffusion de documents scientifiques de niveau recherche, publiés ou non, émanant des établissements d'enseignement et de recherche français ou étrangers, des laboratoires publics ou privés. 


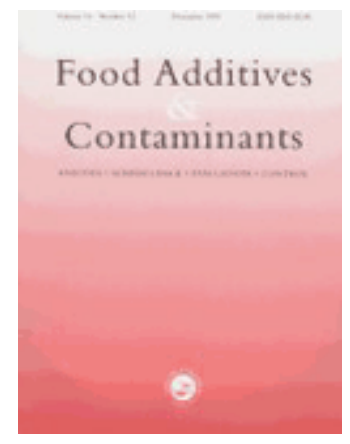

\section{Consumer exposure to phthalates from paper packaging - an integrated approach}

\begin{tabular}{|r|l|}
\hline Journal: & Food Additives and Contaminants \\
\hline Manuscript ID: & TFAC-2009-384.R1 \\
\hline Manuscript Type: & Original Research Paper \\
\hline Author: & 27-Apr-2010 \\
\hline Complete List of Authors: & $\begin{array}{l}\text { Poças, Maria; Biotechnology College - Portuguese Catholic } \\
\text { University, Packaging Department } \\
\text { Oliveira, Jorge; University College Cork, Process and Chemical Eng. } \\
\text { Dept. } \\
\text { Pereira, Joel; Biotechnology College - Portuguese Catholic } \\
\text { University, Packaging Department } \\
\text { Hogg, Timothy; Biotechnology College - Portuguese Catholic } \\
\text { University, CBQF }\end{array}$ \\
\hline Methods/Techniques: & Exposure assessment, Exposure - prob modelling \\
\hline Additives/Contaminants: & Paper, Phthalates, Migration, Packaging \\
\hline Food Types: & Biscuits, Cereals, Confectionary \\
\hline & \\
\hline
\end{tabular}

\section{SCHOLARONE \\ Manuscripts}




\begin{abstract}
This paper presents an integrated approach to estimate exposure of Portuguese population to phthalates as a contaminant originating from paperboard packaging. The approach combined data of migrant concentration in the foods resulting from a stochastic simulation, with consumption data of food packaged in paperboard. The results from the exposure model were validated with experimental values actually found in the food. A short surveillance exercise was conducted with samples collection from the market shelves to identify and quantify the phthalates present in the packages and in the food. The distribution of values for the di-butyl phthalate concentration in the packages was used as input of the initial concentration in the Weibull model to estimate the concentration of this phthalate in the foods. This distribution of occurrence data was then combined with the packaging usage data in a probabilistic simulation with the Monte Carlo sampling method. Exposure values ranged between 0 and $8.95 \mu \mathrm{g} /$ day. $\mathrm{Kg}_{\mathrm{bw}}$, a value close to the tolerable daily intake established by EFSA - $10 \mu \mathrm{g} /$ day. $\mathrm{Kg}_{\mathrm{bw}}$. However, the $97.5^{\text {th }}$ percentile and the average were, respectively, 1.82 and $0.44 \mu \mathrm{g} /$ day. $\mathrm{Kg}_{\mathrm{bw}}$, indicating that further refinement of the estimates is not necessary. Other phthalates were also detected in the packaging samples: di-isobutyl phthalate and di-ethylhexyl phthalate. This latter was present in all packaging samples collected and was detected in a few food samples at values requiring further investigation.
\end{abstract}

Running head:- Probabilistic assessment of exposure to phthalates 


\section{Introduction}

Phthalates are amongst the more commonly found organic contaminants in environment and consumer products. They are used as plasticizers in many plastics applications, including packaging and other food contact materials. Inks, lacquers, adhesives and recycled pulp are important sources of phthalates in paper and paperboard packaging (Aurela et al., 1999; Binderup et al., 2002; Bononi \& Tateo, 2009; Mariani et al, 1999; Sturaro et al., 1995 and 2006). Some phthalates and their metabolites are known to present an endocrine disruptive action that as been associated with impairment of the development of male reproductive system in rodents. Although evidence in humans is still limited, data from human studies have explored possible associations between phthalates and men with altered semen quality, shortened gestation, reduced anogenital distance in baby boys, and premature breast development in young girls (Dickson-Spilmmann et al., 2009; Hauser \& Calafat, 2005; Latini et al., 2003; Swan et al., 2005; Wittassek \& Angerer, 2008). Consequently, exposure to phthalates has been a concern due to these potential health adverse effects.

The work reported here consisted on a surveillance exercise on the phthalates occurrence in paperboard packages and respective foods and on the estimation of Portuguese consumer's exposure to di-butyl phthalate (DBP) originating from paper and paperboard packaging. Exposure can be expressed as (Poças et al., 2007):

Exposure $=$ Migration $x$ Food Consumption

Where the Migration term represents the concentration of substance that, by transfer from the package, ends up in the food; and the term Food Consumption represents the daily intake of food packaged in the system from which the migrant originated, or the amount of packaging used to pack the food consumed, depending on the units used in the Migration term.

Mathematical models are important tools that have been used for compliance assessment of plastics materials, but rarely for paperboard packaging or for generating concentration data for exposure assessments. The generation of values for the distribution of the concentration of migrant in food from a stochastic analysis of the equations governing the migration 


$$
\frac{C(t)-C_{\infty}}{C_{o}-C_{\infty}}=\exp \left[-\left(\frac{t}{\tau}\right)^{\beta}\right]
$$

Where $C(t)$ is the concentration of migrant in food changing with time $t, C_{\infty}$ is the concentration at equilibrium and $C_{o}$ is the initial concentration. The model has two parameters: $\tau$, the scale parameter, associated to the process rate, being the time required accomplish a one log cycle $(63,8 \%)$ of the process; and $\beta$ is the shape parameter, quantifying the pattern of curvature observed (Cunha et al., 2001). When applying this model to migration of a contaminant, its initial concentration in the food can be considered equal to zero. Normalising the migrant concentration in the food, $C(t)$, with the initial migrant concentration in the package $C_{0}^{P}$, gives:

$$
\frac{C^{F}(t)}{C_{o}^{P}}=\frac{C_{\infty}^{F}}{C_{o}^{P}}\left[1-\exp \left(-\left(\frac{t}{\tau}\right)^{\beta}\right)\right]
$$

The model parameters $\left(\tau, \beta, C_{\infty}^{F} / C_{o}^{p}\right)$ determined before (Poças, 2009) were used and the initial concentration of DBP $\left(C_{o}^{P}\right)$ in the cellulosic packaging materials was determined experimentally from a short market survey. Samples of packages were collected from the shelves and screened for phthalates detection followed by quantification. Equation (3) was used to generate the $C^{F}$ distribution of values required for the $1^{\text {st }}$ term of the exposure equation (1). 
The consumption of food that is in contact with paper or paperboard is the other term in the exposure equation (1). The packaging usage data of a Portuguese representative consumers sample gathered before was used (Poças et al., 2009). The exposure model can then be expressed as follows:

$$
E\left(m g / d a y . K g_{b w}\right)=C^{F}\left(m g / K g_{\text {food }}\right) x F W\left(K g / d a y . K g_{b w}\right)
$$

Where $F W$ is the food weight packaged in paperboard consumed per day and per consumer body weight. Both terms of equation (4), for migrant concentration and for food consumption, are represented by distributions of values for a probabilistic analysis. The exposure to DBP is simulated through the propagation of the variables distribution through the model with the Monte Carlo (MC) sampling method. The results of the model were validated with DBP concentration data from the food samples collected in the market.

\section{Materials and methods \\ Data of initial concentration of DBP in the packaging}

A short survey of the local market was conducted: samples of paper and paperboard packages were collected and taken to the laboratory for screening analyses: phthalates present were identified and semi-quantified as described subsequently.

\section{- Sample}

Foods (21) packaged in cellulosic materials were purchased in one supermarket in Gaia, Portugal, in April 2009 (Table 1). Food products were mostly dried food such as cookies and biscuits, flour and sugar, cereals and dry pasta, but also butter, frozen ice cream and chocolate. The foods all had primary or secondary packages made of paper, paperboard or corrugated board. In most cases there was also an inner package in paper or in a different material and only a few products were in direct contact with the outer packaging.

\section{- Sample preparation}

Packaging materials (only the cellulose based) and food samples were extracted with hexane, followed by sonication for $30 \mathrm{~min}$ and filtration. Around $1 \mathrm{~g}$ of packaging material 


\section{- Semi-quantification of phthalates}

The amount of each phthalate in the packaging material was quantified in relation to the amount of d-DHP. This internal standard $(100 \mathrm{mg} / \mathrm{L})$ was added to the extract in the amount required to yield a concentration of $1 \mathrm{mg} / \mathrm{l}$. This corresponded to a concentration of $5 \mathrm{mg} / \mathrm{Kg}$ of packaging materials and to concentrations in food between 1 and $3 \mathrm{mg} / \mathrm{Kg}$. Because the purpose of the study was first to identify the type of phthalates present in market packages, the full scan mode was used in MS detection rather than the selected ions mode that would allow for a more accurate and sensitive quantification of known phthalates. Detection limits of $0.04 \mathrm{mg} / \mathrm{L}$ were found for DiBP, DEHP and DBP in hexane extracts that corresponded, for the extraction conditions observed, to $0.2 \mathrm{mg} / \mathrm{Kg}$ of packaging material and to 0.04 to 0.12 $\mathrm{mg} / \mathrm{Kg}$ of foods. Precautions during sample and chemicals handling were taken to avoid blank problems with phthalate contamination: the system and all the material contacting samples were routinely run and rinsed for cleaning. Glassware was washed with acetone and non-volumetric material was left at $105-110{ }^{\circ} \mathrm{C}$ for at least 4 hours before use. Injections of blanks from solvents of extractions were accepted, as an indication of clean system, only with non detected phthalates (ratio signal/noise lower than 3).

\section{- Chromatographic conditions for phthalates screening}

Chromatograph Varian CP-3800 with detector Quadrupole MS 1200L (Ionisation mode: electronic impact $70 \mathrm{eV})$; Scan mode: full scan (m/z 90 to $300 \mathrm{~m} / \mathrm{z}$ )

Column: Varian fused silica capillary VF-5MS (30 m x $0.25 \mathrm{~mm}, 0.25 \mu \mathrm{m}$ )

Temperature of the injector: $300^{\circ} \mathrm{C}$ 
Oven: $60^{\circ} \mathrm{C}$ during $1 \mathrm{~min} ; 10^{\circ} \mathrm{C} / \mathrm{min}$. up to $320^{\circ} \mathrm{C}$ and $320^{\circ} \mathrm{C}$ during $5 \mathrm{~min}$

Volume of injection: $1 \mu$ l split:splitless (splitless time $0.5 \mathrm{~min}$ )

The chromatographic system used presents typically determination coefficients better than $\mathrm{R}^{2}>0.99$ for all phthalates and the average variation between repeated injections was lower than $4 \%$.

Packaging usage data: the database from MIGRAMODEL project (ESB, 2008) was used to provide data on the amount of food in contact with paper and paperboard packages; this database includes data collected at household level. The food weight consumed per day and per consumer body weight was derived. The average amount of paper and paperboard packaging usage for food eaten at home in the consumer sample was ca $2 \mathrm{dm}^{2} /$ day.person. This value corresponded to $0.11 \mathrm{Kg}$ of food packaged in cellulosic material consumed per day and per person. When the household bodyweight is taken into consideration, the average value is $0.002 \mathrm{Kg}_{\text {food }} /$ day. $\mathrm{Kg}_{\text {bw }}$ (Poças et al. 2009). Figure 1 represents the distribution of values found that were best fitted to the lognormal probability distribution function (Table 2).

\section{Weibull model parameters}

The following Weibull model parameters were considered to describe the migration of DBP at $23^{\circ} \mathrm{C}: \tau(\mathrm{hr})=49.6 \pm 10.5, \beta=1.35 \pm 0.32$ and $C^{F}{ }_{\alpha} / C^{P}{ }_{o}=0.184 \pm 0.020$. These parameters were derived from migration experiments from paper into Tenax ${ }^{\circledR}$ (Poças, 2009). These parameters were considered normally distributed and propagated in equation (3) to generate a distribution of values for the concentration of DBP in food.

\section{Probabilistic analysis}

The software Crystal Ball 7.2.2. (Decisioneering, Inc.) was used to fit the exposure model inputs (food consumption data and DBP concentration data) as well as the model output to probability distributions functions by the maximum likelihood method. The distributions were truncated to allow only positive values in the exposure model because there is no physical meaning for negative values of these inputs. The goodness-of-fit was assessed by the Anderson-Darling (A-D) test. MC simulation was used as sampling method with 10000 iterations for each run. This sample size is suggested in principles of good practice for MC 


\section{Results and discussion}

i. Phthalates concentration in packaging samples

All packaging samples collected and all corresponding foods were analysed. Phthalates were detected in all packaging samples but they were detected in only some of the food samples. Table 3 presents the concentration of each phthalate detected in the outer packaging materials collected and in the foods contained in each packaging system. Three phthalates were found in most of the packaging samples in concentrations typically lower than 20 mg/Kg: DEHP (Diethyl hexyl phthalate; CAS 117-81-7), DiBP (Diisobutyl phthalate; CAS 84-695) and DBP (Dibutyl phthalate; CAS 84-74-2). DEHP was present in all samples in concentrations ranging from 0.5 to $5 \mathrm{mg} / \mathrm{Kg}$. DiBP presented the highest average concentration in the packaging samples: values ranged from 0.1 to $21 \mathrm{mg} / \mathrm{kg}$; the highest value was found in sample P7. DBP concentration values ranged from 0.4 to $3 \mathrm{mg} / \mathrm{Kg}$. DEP (Diethyl phthalate; CAS 84-66-2) was detected in one packaging sample (P4). In sample P7 DINP was additionally detected (Diisononyl Phthalate; CAS 28553-12-0) in a concentration of ca. $21 \mathrm{mg} / \mathrm{kg}$.

The values found for DBP in the packaging samples can be compared with the values found in a recent USA survey, which showed values ranging from 0.14 to $55 \mathrm{mg} / \mathrm{kg}$, with most of the individual values lower than $20 \mathrm{mg} / \mathrm{kg}$ (Zhang et al., 2008). DIBP was also found in Italian restaurants take-away pizza boxes (Bononi \& Tateo, 2009). However, the values cannot be directly compared because the results were given per unit of box surface area and not for mass of board. Summerfiled \& Cooper (2001) also found the same three phthalates in towels and napkins collected from UK market in concentrations of 12 to $21 \mathrm{mg} D E H P / \mathrm{kg}, 3$ to $10 \mathrm{mg}$ DiBP/kg and 2 to $3 \mathrm{mg} \mathrm{DBP} / \mathrm{kg}$. Aurela et al. (1999) found considerably higher values: 8 to $430 \mathrm{mg} \mathrm{DEHP} / \mathrm{kg}, 30$ to $450 \mathrm{mg} \mathrm{DiBP} / \mathrm{kg}$ and 7 to $130 \mathrm{mg} \mathrm{DBP} / \mathrm{kg}$. This is not surprising because there has been a general effort in reducing the exposure levels of consumers to this group of chemicals in the past decade. Those authors had found at that time that most of the cases detected were associated to off-set printing and that DEHP was the more common 
phthalate. A few samples were flexo-printed and contained significant amount of DBP and DiBP (Aurela et al., 1999).

A survey in Australian market (1996-1997) to 136 food packaging materials including plastics, presented average values for the DBP and DEHP in printed fibre board packaging for baked foods, respectively 58 and $320 \mathrm{mg} / \mathrm{kg}$, and in boxes for breakfast cereals average values of 45 and $42 \mathrm{mg} / \mathrm{kg}$. these two phthalates were present and nearly all packaging samples. The values found in paper tea bags were considerably higher: $550 \mathrm{mg} / \mathrm{Kg}$ for DBP and 1625 $\mathrm{mg} / \mathrm{Kg}$ for DEHP (Balafas et al., 1999).

In a recent analysis of phthalates in infant food (milk powders, cereal flakes and semolina powder) packaged in recycled paperboard collected in Germany, four phthalates were detected in all samples: DIBP, DBP, BBP and DEHP. Values found in this survey tend to be higher because the sampling targeted packages made of recycled board which did not necessarily happen in the present study. The average value found to DIBP was $23 \mathrm{mg} / \mathrm{kg}$, the values to DEHP ranged from 0.5 to $17 \mathrm{mg} / \mathrm{kg}$ and the values for DBP were all lower than 6 $\mathrm{mg} / \mathrm{kg}$ (Gärtner et al., 2009).

Although only 21 samples have been collected, the distribution of values found for the DBP detected in the packaging samples is shown in Figure 2. The samples presenting nodetectable DBP were attributed with a value equal to $0.01 \mathrm{mg} / \mathrm{kg}$ (a fraction of the quantification limit). This explains the high frequency of the lowest concentration bin in the histogram. Figures 3 and 4 show the distribution values of DEHP and DiBP concentration, respectively.

\section{ii. DBP exposure estimates}

Table 2 presents the results for the distribution functions fitting the input variables for the DBP exposure model according to equation (3): food weight packaged in cellulosic materials (FW) and the result of the market survey on DBP concentration in the packages that was used in the migration Weibull model to generate the data for the $C^{F}$ term in the exposure equation (3). 
The Weibull model was run to generate DBP concentration values after 1 month of contact between the package and the food. This period of time was selected taking into consideration the expected average shelf-life of the products. In fact, the Weibull model parameters used were derived from experiments where the packaging material was in direct contact with Tenax ${ }^{\circledR}$. In those conditions, 1 month of migration time yields to the maximum (equilibrium) concentration of DBP as can be seen through a simple simulation using the model parameters given. In that range of concentration, considering different product shelflife would not affect the exposure estimates (Poças et al., 2010). Furthermore, some of the food packaging systems used presented a primary package made of a better barrier material than paper. That layer acts as a "delaying" barrier, promoting a lag-phase in the migration curve. Therefore, at any time of contact, those foods present a DBP concentration lower than that predicted by the model for the same time of contact.

Figure $5(A)$ and $(B)$ presents the output of $M C$ simulation of the $C^{F} / C^{P}$ ond $C^{F}$, respectively. Descriptive statistics for the DBP concentration in the food and for the exposure estimates are presented in Table 4. Estimates of concentration of DBP in food indicate a mean of ca. $0.21 \mathrm{mg} / \mathrm{kg}_{\text {food }}$ with a maximum estimated value of ca. $0.6 \mathrm{mg} / \mathrm{kg}_{\text {food. }}$. The $97.5^{\text {th }}$ percentile is at $0.46 \mathrm{mg} / \mathrm{Kg}_{\text {food }}$ as indicated in Figure $5(\mathrm{~B})$. If one takes as reference the limit for specific migration of DBP set in Directive $2007 / 19 /$ CE for plastic, which is $0.3 \mathrm{mg} / \mathrm{kg}_{\text {food, }}$ the estimates indicate a $33 \%$ risk of finding higher values in the market samples.

The distribution of exposure values is presented in Figure 6. The curve presents a nonnormal shape, exponential decreasing: the probability of exposure decreases as the exposure value increases. Exposure values ranged from 0 to $8.95 \mu \mathrm{g} / \mathrm{day} \cdot \mathrm{kg}_{\mathrm{bw}}$, thus presenting values close to the TDI established by EFSA in 2005 , which is $10 \mu \mathrm{g} /$ day. $\mathrm{Kg}_{\mathrm{bw}}$. However, the $97.5^{\text {th }}$ percentile is $1.82 \mu \mathrm{g} /$ day. $\mathrm{kg}_{\mathrm{bw}}$ and the mean is estimated as 0.44 $\mu \mathrm{g} /$ day. $\mathrm{kg}_{\mathrm{bw}}$, values considerably lower than TDI, indicating that probably no further refinement is required.

In order to validate the results of the exposure estimates, the actual values for the DBP phthalates in the food samples were also screened in order to verify that the phthalates concentration in the foods obtained by simulation are not lower then the values determined 
experimentally. The results for the food samples presenting detectable values of phthalates concentration are also presented in Table 3.

DiBP and DEHP were detected in 3 food samples and DBP, DINP or DEP were not detected under the conditions of test. DIBP was found at a concentration of $0.37 \mathrm{mg} / \mathrm{kg}$ in flour and at ca $0.15 \mathrm{mg} / \mathrm{kg}$ in a cake mix and tea. DIBP is not regulated yet by EFSA and it has been assigned to SCF List 8 (list of substances evaluated or under evaluated by EFSA), thus indicating that there is no adequate data for a scientifically sound decision on the safe use of this substance. Past evaluations by SCF indicated a group restriction of $0.05 \mathrm{mg} / \mathrm{kg}_{\mathrm{bw}}$.day for its use in plastics materials (EFSA, 2004). In the meanwhile, the German safety authority (BfR) has recommended a specific restriction of migration into foods of $1 \mathrm{mg} / \mathrm{kg}_{\text {food }}$ and suggested that German industry should agree on a common strategy to reduce and phase out the use of glues, printing inks and other products containing DIBP in order to reduce its levels in recycled paper (BfR, 2007). In 2009, FEFCO (European Federation of Corrugated Board Manufacturers) has also reached a voluntary agreement to phase out DiBP from corrugated products. The concentration values found in the food samples collected are around $1 / 3^{\text {rd }}$ and $1 / 10^{\text {th }}$ of the recommended by $B f R$, therefore a wider and precise survey is not necessarily required.

DEHP was found at a concentration of $0.06 \mathrm{mg} / \mathrm{kg}$ in a cake mix, $0.2 \mathrm{mg} / \mathrm{kg}$ in stocks and at a concentration of $2.2 \mathrm{mg} / \mathrm{kg}$ in butter. In this latter case, the Al/paper wrapping materials was in direct contact and the value exceeded the migration limit set in the Directive 2002/19/EC which is $1.5 \mathrm{mg} / \mathrm{kg}$. This limit is applicable to all-plastic materials and therefore it is not applicable (in legal terms) to the present case. The sample analysed was collected from the surface of the butter piece, which represents a worst case. Nevertheless, this particularly high value found may indicate that a more refined survey is necessary.

Given the result for DBP (not detected in the food samples), the exposure estimates may be considered safe. As indicated in Table 1, many samples had a primary inner packaging that acts as a barrier between the outer cellulosic package and the food. The Weibull model parameters were derived for situations where paper is in direct contact, thus it could be anticipated that an overestimation of the DBP concentration of the food and hence of the 


\section{Conclusions}

The combination of mathematical models with food packaging usage data can be a practical and efficient tool to be considered in exposure assessments. The benefit of using these simulation tools is particularly interesting to avoid the analytical difficulties inherent to food matrices. Data of initial concentration in the packaging materials are still required but these are easier to obtain either through expert judgement or even by analytical means that, depending on the migrant, are typically simpler than those required to analyse food samples. The use of mathematical models requires the knowledge of the model parameters and for this study only the DBP parameters were available. The study should be extended to DiBP and DEHP when Weibull model parameters are available.

The parameters of the mathematical model used in the present study were derived with an experimental set up where the cellulosic material was in direct contact with the food simulant Tenax ${ }^{\circledR}$ (Poças, 2009). In those conditions migration is very fast because migrants do not need to cross a high barrier material. Furthermore, Tenax ${ }^{\circledR}$ is considered to be an adequate simulant of solids foods for compliance purposes as experience indicates that equilibrium concentration in this simulant is often higher than the equilibrium concentration found in actual foods, thus indicating that results obtained with the simulant have a safe margin. Therefore, using the model parameters obtained in the described conditions to simulate concentration values that occur in real food and non direct contact, yields simulated concentration values in the food that are higher and that are achieved faster than those that would be achieved in actual conditions of indirect contact with food. Consequently the exposure model yields overestimated exposure values. 
Survey results indicate that DEHP is omni-present and that depending on the packaging system it may migrate into the food in quantities that become close to safety limits. This phthalate may justify a more specific study, first with the mathematical model as a source of concentration data and depending on the results a more extensive sample collection from the market could be made.

\section{References}

Aurela, B.; Kulmala, H.; Soderhjelm, L. 1999. Phthalates in paper and board packaging and their migration into Tenax and sugar. Food Additives \& Contaminants, 16 (12), 571-577.

Balafas, D.; Shaw, K.J.; Whitfield, F.B. 1999. Phthalate and adipate esters in Australian packaging materials. Food Chemistry, 65, 279-287.

BfR 2007. Di-isobutyl phthalate in food contact paper and board. Minutes of the Meeting of the WG Paper \& Board, July 2007. [cited 29 October 2009] Available from

www.bfr.bund.de/cm/230/di isobutyphthalate in food contact paper and board.pdf

Binderup, M.-L; Pedersen, G.A.; Vinggaard, A.M.; Rasmussen, E.S.; Rosenquist, H.; Cederberg, T. 2002. Toxicity testing and chemical analysis of recycled fibre-based paper for food contact. Food Additives \& Contaminants, 19 (Suppl.), 13-28.

Blasco, M.; Garcia-Pérez, J.V.; Bon, J.; Carreres, J.E.; Mulet, A. 2006. Effect of blanching and air flow rate in turmeric drying. Food Science and Technology International, 12(4), 315-323.

Bononi, M.; Tateo, F. 2009. Identification of Diisobutyl Phthalate (DIBP) Suspected as Possible Contaminant in Recycled Cellulose for Take-away Pizza Boxes, Packaging Technology and Science, 22: 53-58.

Burmester, D.E.; Anderson, P.D. 1994. Principles of food practice for the use of MonteCarlo techniques in human health and ecological risk assessment. Risk Analysis, 14: 477-481.

Cunha, L.M.; Oliveira, F.A.R.; Aboim, A.; Frías, J.; Pinheiro-Torres, A. 2001. Stochastic approach to the modelling of water losses during osmotic dehydration and improved parameter estimation. International Journal of Food Science and Technology, 36, 253-262.

Dickson-Spillmann, M.; Siegrist, M.; Keller, C.; Wormuth, M. 2009. Phthalate exposure through food and consumers' risk perception of chemicals in food. Risk Analysis, 29(8):11701181.

EFSA (European Food Safety Authority). 2004. Statement of the Scientific AFC Panel on the re-classification of some phthalates for consistency with new SCF guidelines for food contact materials. Parma: European Food Safety Authority. 
ESB (Escola Superior de Biotecnologia). 2008. Household survey on food packaging. Project Final Report Mathematical modelling for exposure assessment and compliance of safety requirements, Catholic University, Porto. www.esb.ucp.pt/EmbalagemMigramodel/

Freitas, M.A.; Costa, J.C. 2006. Shelf life determination using sensory evaluation scores: A general Weibull modelling approach. Computers and Industrial Engineering, 51(4), 652-670.

Gärtner, S.; Balsky, M.; Koch, M.; Nehls, I. 2009. Analysis and Migration of Phthalates in Infant Food Packed in Recycled Paperboard. J. Agric. Food Chem., 57, 10675-10681.

Hauser, R.; Calafat, A.M. 2005. Phthalates and human health. Occupational and Environmental Medicine, 62, 806-818.

Latini, G.; De Felice, C.; Presta, G.; Del Vecchio, A.; Paris, I.; Ruggieri, F.; et al. 2003. In uterus exposure to di-(2-ethylhexyl) phthalate and duration of human pregnancy. Environmental Health Perspectives, 111(14), 1783-1785.

Mariani, M.B.; Chiacchierini, E.; Gesumundo, C. 1999. Potential migration of Diisopropyl naphthalenes from recycled paperboard packaging into dry foods. Food Additives \& Contaminants 16(5), $207-213$.

Morales, M.E.; Lara, V.G.; Calpena, A.C.; Doménech, J.; Ruiz, M.A. 2004. Comparative study of morphine diffusion from sustained release polymeric. Journal of Controlled Release, 95, 75-81.

Poças, M.F.F.; Hogg, T. 2007. Exposure assessment of chemicals from packaging materials in foods: a review. Trends in Food Science \& Technology, 18, 219-230.

Poças, M.F.F.; Oliveira, J.C.; Pinto, H.J.; Zacarias, M.E.; Hogg, T. 2009. Characterization of patterns of food packaging usage in Portuguese homes. Food Additives and Contaminants, 26 (9), 1314-1324.

Poças, M.F.F. 2009. Analysis of Migration from Food Packaging into Foods: Probabilistic Modelling and Assessment of Consumer Exposure. PhD Thesis. Porto, Biotechnology College: Portuguese Catholic University http://www.esb.ucp.pt/biblio/

Poças, M.F.F.; Oliveira, J.C.; Brandsch, B.; Hogg, T. 2010. Feasibility study on the use of probabilistic migration modeling in support of exposure assessment from food contact materials. Risk Analysis, (in press).

Sturaro, A.; Parvoli, G.; Rella, R.; Doretti, L. 1995. Hydrogenated terphenyls contaminants in recycled paper. Chemosphere, 30, 687-694.

Sturaro, A.; Rella, R.; Parvoli,G.; Ferrara, D.; Tisato, F. 2006. Contamination of dry foods with trimethyldiphenylmethanes by migration from recycled paper and board packaging. Food Additives \& Contaminants, 23 (4), 431-436. 
Summerfield, W.; Cooper, I. 2001. Investigation of migration from paper and board into food-development of methods for rapid testing. Food Additives \& Contaminants 18(1):77 88.

Swan, S.H.; Main, K.M.; Liu, F.; Stewart, S.L.; Kruse, R.L.; Calafat AM, et al. 2005. Decrease in anogenital distance among male infants with prenatal phthalate exposure. Environmental Health Perspectives, 113(8), 1056-1061.

Vitrac, O.; Leblanc, J-C. 2007. Consumer exposure to substances in plastic packaging. I. Assessment of the contribution of styrene from yogurt pots. Food Additives \& Contaminants, 24(2), 194-215.

Wittassek, M.; Angerer, J. 2008. Phthalates: metabolism and exposure. International Journal of Andrology, 31, 131-138.

Zhang, K.; Noonan, G. O.; Begley, T. H. 2008. Determination of 2,6-diisopropylnaphthalene (DIPN) and n-dibutylphthalate (DBP) in food and paper packaging materials from US marketplaces. Food Additives \& Contaminants, 25 (11), 1416-1423. 


\section{List of tables}

Table 1. List of food samples and corresponding packaging system.

Table 2. Parameters of functions describing the distribution of values of the exposure model inputs.

Table 3. Concentration $(\mathrm{mg} / \mathrm{Kg}$ ) of phthalates found in the packaging samples and in the respective food samples.

Table 4. Descriptive statistics for the DBP concentration in food simulated with the Weibull model and for the exposure model output.

List of Figures

Figure 1. Food consumed packaged in paper and paperboard (Data from ESB (2008)).

Figure 2. Concentration of DBP in packages collected from the market.

Figure 3. Concentration of DEHP in packages collected from the market.

Figure 4. Concentration of DiBP in packages collected from the market.

Figure 5. Weibull model output: $(A)$ - ratio of $D B P$ concentration in the food to the initial concentration in the paper; (B) - DBP concentration in the food.

Figure 6. Estimates of exposure to DBP from food packaged in paper and board. 
Table 1. List of food samples and corresponding packaging system.

\begin{tabular}{|c|c|c|c|c|}
\hline Code & Packaging & Food Contact & Inner packaging & Product \\
\hline P1 & Carton box & $\mathrm{N}$ & Paper pouch & Cake mix \\
\hline P2 & Carton box & $\mathrm{N}$ & Al/paper wrap & Stocks \\
\hline P3 & Carton box & $\mathrm{N}$ & Al/paper wrap & Chocolate \\
\hline P4 & Carton box & $\mathrm{N}$ & $\begin{array}{l}\text { Plastic pouch/tea } \\
\text { bag }\end{array}$ & Tea \\
\hline P5 & Carton box & $\mathrm{N}$ & Plastic pouch & Biscuits \\
\hline P6 & Carton box & $\mathrm{N}$ & Al/paper wrap & Stocks \\
\hline P7 & Carton box & $\mathrm{N}$ & Plastic pouch & Biscuits \\
\hline P8 & Carton box & $\mathrm{N}$ & Paper pouch & Flour \\
\hline P9 & Carton box & $\mathrm{N}$ & Plastic pouch & Biscuits \\
\hline P10 & Carton box & $N$ & $\begin{array}{l}\text { Metallized plastic } \\
\text { pouch }\end{array}$ & Flour \\
\hline P11 & Carton box & $\mathrm{N}$ & Plastic pouch & Breakfast cereals \\
\hline P12 & Paper bag & $Y$ & No & Sugar \\
\hline P13 & Paper bag & $\mathrm{Y}$ & No & Flour \\
\hline P14 & Carton box & $\mathrm{N}$ & Plastic pouch & Breakfast cereals \\
\hline P15 & Carton box & $\mathrm{N}$ & Al wrap & Chocolate \\
\hline P16 & Carton box & $\mathrm{N}$ & $\begin{array}{l}\text { Metallized plastic } \\
\text { pouch }\end{array}$ & Biscuits \\
\hline P17 & Carton box & $\mathrm{Y}$ & No & Dry pasta \\
\hline P18 & $\begin{array}{l}\text { Composite } \\
\text { can }\end{array}$ & $\mathrm{Y}$ & No & Snack \\
\hline P19 & Folding carton & $\mathrm{N}$ & HDPE bottle & Yogurt \\
\hline P20 & Flexible wrap & $Y$ & Al/paper wrap & Butter \\
\hline P21 & $\begin{array}{l}\text { Corrugated } \\
\text { board box }\end{array}$ & $\mathrm{N}$ & Plastic pouch & Ice cream \\
\hline
\end{tabular}


Table 2. Parameters of functions describing the distribution of values of the exposure model inputs.

\begin{tabular}{cccl}
\hline Variable & Distribution & A-D & \multicolumn{1}{c}{ Parameters } \\
\hline FW & Lognormal & 0.1317 & $\begin{array}{l}\text { Mean }=0.0021 \\
\text { Std. Dev. }=0.00169 \\
\text { Location }=-0.00022 \\
\text { Minimum }=-0.07777\end{array}$ \\
& Beta & \multirow{2}{*}{0.6098} & $\begin{array}{l}\text { Maximum }=2.29386 \\
\text { Alpha }=0.42416 \\
\text { Beta }=0.55836\end{array}$ \\
& &
\end{tabular}


Table 3. Concentration $(\mathrm{mg} / \mathrm{Kg}$ ) of phthalates found in the packaging samples and in the respective food samples.

\begin{tabular}{|c|c|c|c|c|c|}
\hline Sample & DiBP & DBP & DEHP & DEP & DINP \\
\hline P1 & 2.3 & 0.68 & 1.2 & & \\
\hline P2 & 3.9 & 1.3 & 1.8 & & \\
\hline P3 & 0.15 & & 0.46 & & \\
\hline P4 & 12 & 0.79 & 1.9 & 0.28 & \\
\hline P5 & 8.3 & 0.88 & 5.1 & & \\
\hline P6 & 4.0 & 2.1 & 3.5 & & \\
\hline P7 & 21 & 1.6 & 3.9 & & 21 \\
\hline P8 & 7.9 & 2.2 & 3.5 & & \\
\hline P9 & 3.3 & 0.79 & 3.1 & & \\
\hline P10 & 5.2 & 1.8 & 2.8 & & \\
\hline P11 & 5.4 & 0.99 & 3.0 & & \\
\hline P12 & 2.6 & 0.45 & 1.3 & & \\
\hline P13 & 0.43 & & 0.60 & & \\
\hline P14 & 8.9 & 2.3 & 3.7 & & \\
\hline P15 & 1.0 & & 0.52 & & \\
\hline P16 & 3.9 & & 2.9 & & \\
\hline P17 & 4.3 & & 0.82 & & \\
\hline P18 & 7.7 & 1.9 & 3.6 & & \\
\hline P19 & & & 2.1 & & \\
\hline P20 & & & 1.6 & & \\
\hline P21 & 16 & 2.0 & 4.5 & & \\
\hline F1 & 0.16 & & 0.063 & & \\
\hline F2 & & & 0.19 & & \\
\hline F4 & 0.14 & & & & \\
\hline F8 & 0.36 & & & & \\
\hline F20 & & & 2.2 & & \\
\hline
\end{tabular}


Table 4. Descriptive statistics for the DBP concentration in food simulated with Weibull model and for the exposure model output.

\begin{tabular}{lrr}
\multicolumn{1}{c}{ Statistics } & $C^{F}, \mathrm{mg} / \mathrm{Kg} f_{\text {ood }}$ & $E, \mathrm{mg} / \mathrm{day} . \mathrm{Kg}_{\mathrm{bw}}$ \\
\hline Trials & 10000 & 10000 \\
Mean & 0.211 & 0.000439 \\
Standard Deviation & 0.144 & 0.000522 \\
Variance & 0.021 & 0.000000 \\
Skewness & 0.127 & 3.27 \\
Kurtosis & 1.71 & 24.12 \\
Coeff. of Variability & 0.682 & 1.19 \\
Minimum & 0.000 & 0.000000 \\
Maximum & 0.579 & 0.008947 \\
Range Width & 0.579 & 0.008947 \\
Mean Std. Error & 0.0014 & 0.000005 \\
\hline
\end{tabular}




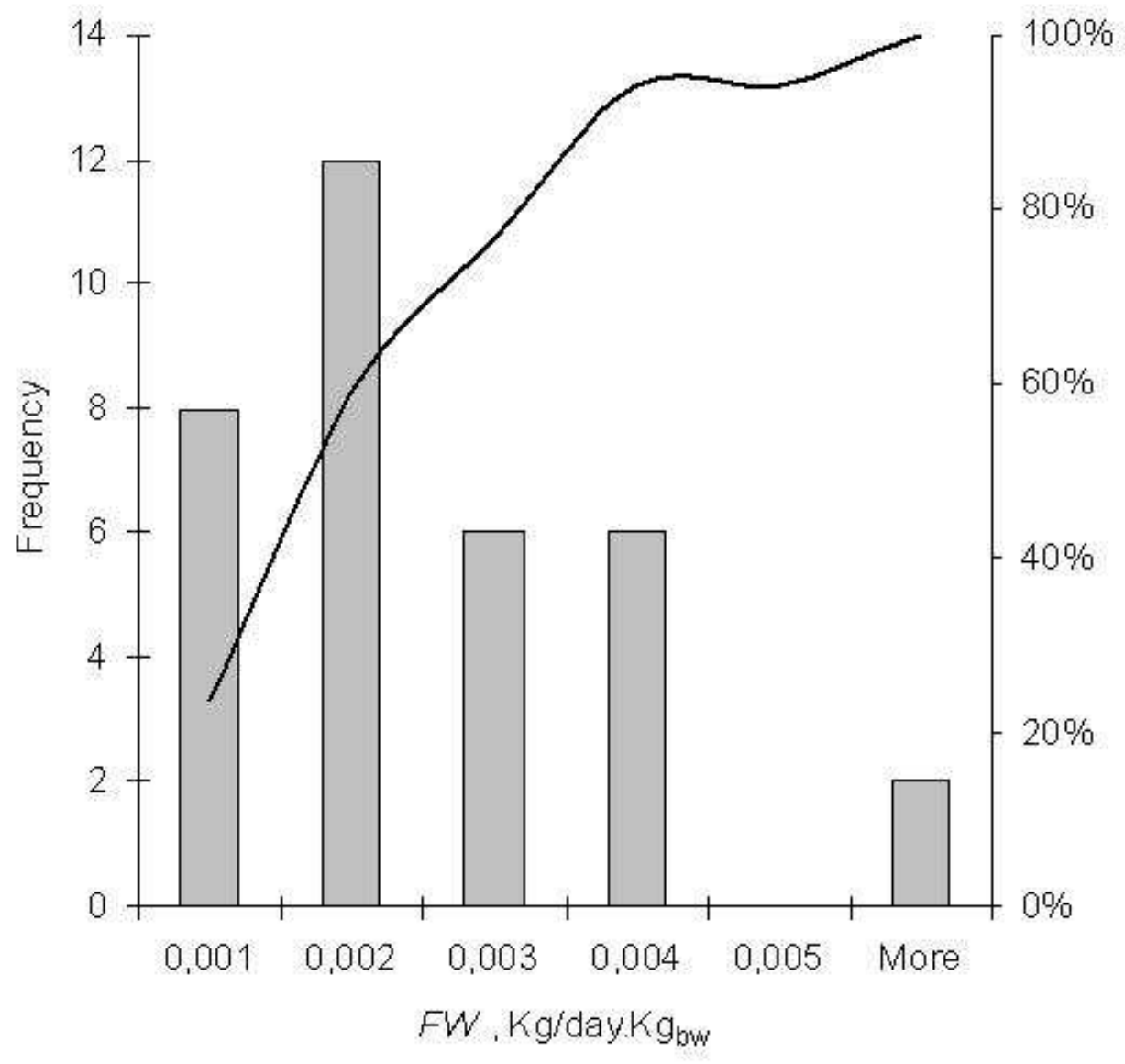

Figure 1. Food consumed packaged in paper and paperboard (Data from Poças et al., 2009). $145 \times 138 \mathrm{~mm}(96 \times 96 \mathrm{DPI})$ 


1
2
3
4
5
6
7
8
9
10
11
12
13
14
15
16
17
18
19
20
21
22
23
24
25
26
27
28
29
30
31
32
33
34
35
36
37
38
39
40
41
42
43
44
45
46
47
48
49
50
51
52
53
54
55
56
57
58
60

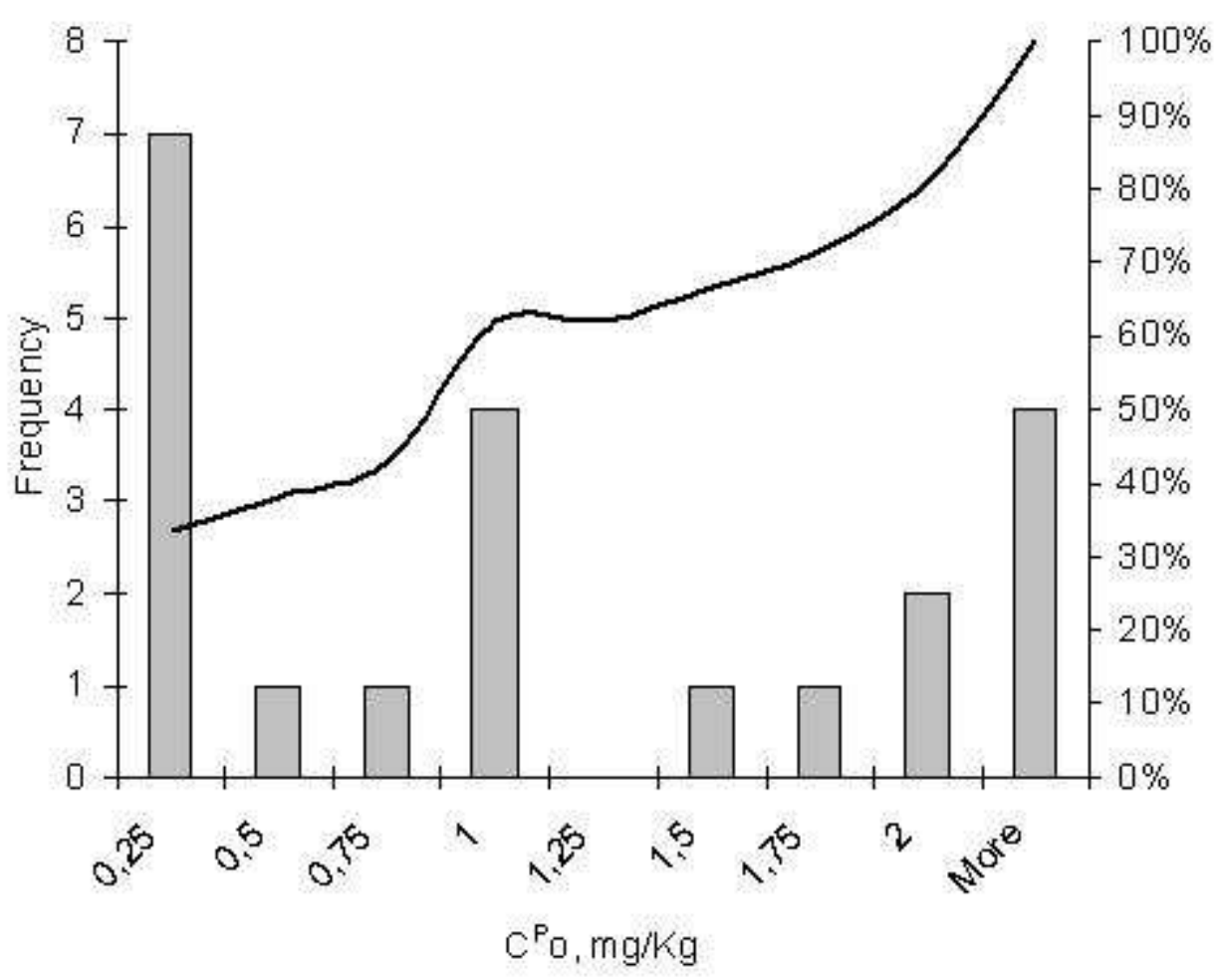

Figure 2. Concentration of DBP in packages collected from the market. $130 \times 105 \mathrm{~mm}(96 \times 96 \mathrm{DPI})$ 


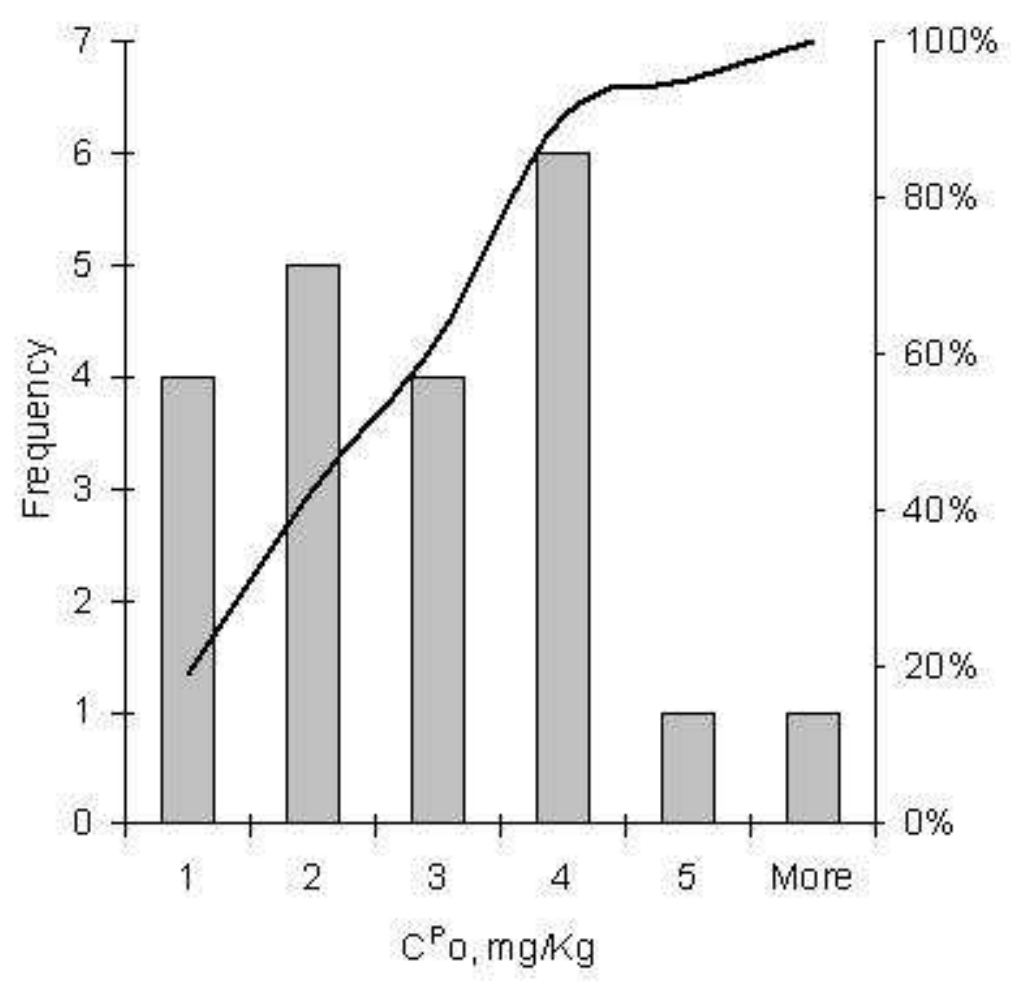

Figure 3. Concentration of DEHP in packages collected from the market. $107 \times 104 \mathrm{~mm}(96 \times 96 \mathrm{DPI})$ 


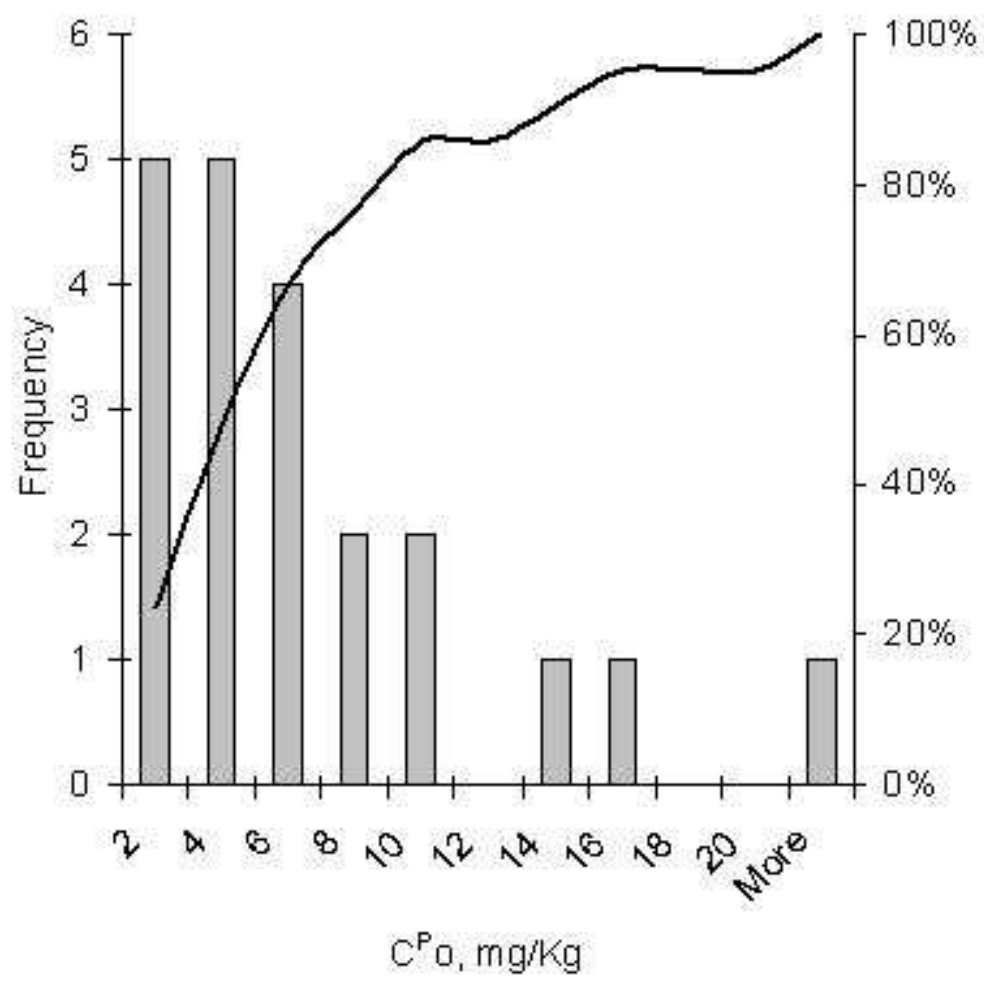

Figure 4. Concentration of DiBP in packages collected from the market. $107 \times 106 \mathrm{~mm}(96 \times 96 \mathrm{DPI})$ 

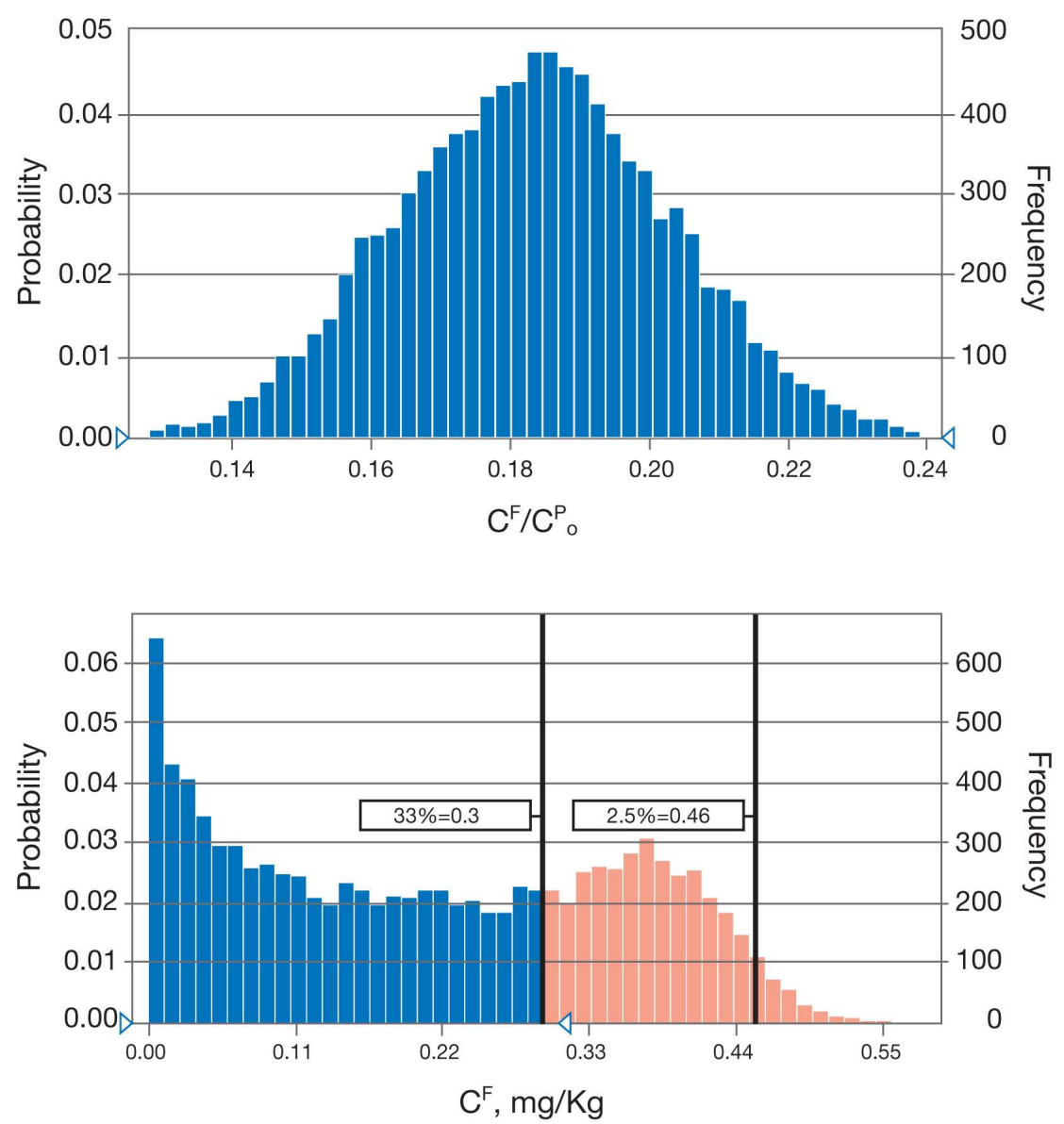

Figure 5. Weibull model output: $(A)$ - ratio of DBP concentration in the food to the initial concentration in the paper; $(B)$ - DBP concentration in the food. $165 \times 168 \mathrm{~mm}(300 \times 300 \mathrm{DPI})$ 
Figure 6. Estimates of exposure to DBP from food packaged in paper and board. $165 \times 80 \mathrm{~mm}(300 \times 300 \mathrm{DPI})$ 